\title{
STUDY OF PREPARATION AND PHOTOLUMINESCENCE PROPERTY OF MOLYBDATE PHOSPHORS FOR WHITE LED
}

\author{
Kong Li, Wang Wensheng, Liu Yingying, Qiao Lu, Wei Qiye* \\ Institute of Petrochemical Technology, Jilin Institute of Chemical Technology, Jilin 132022, China. \\ *Corresponding Author Email: lkong99@163.com
}

This is an open access article distributed under the Creative Commons Attribution License, which permits unrestricted use, distribution, and reproduction in any medium, provided the original work is properly cited

\section{ARTICLE DETAILS}

Article History:

Received 26 June 2018

Accepted 2 july 2018

Available online 1 August 2018

\begin{abstract}
$\mathrm{Eu}^{3+}$ doped $\mathrm{SrMoO}_{4}$ phosphors were synthesized through the high-temperature solid-state reaction method and characterized with X-ray diffraction, photoluminescence emission and photoluminescence excitation spectra. The color coordinates is calculated. The optimum concentration of $30 \%$ is determined by adjusting the concentration of $\mathrm{Eu}^{3+}$.The effects of charge compensator type and concentration on the luminescent properties of phosphor are studied. The result shows that the addition of $\mathrm{Na}_{2} \mathrm{CO}_{3}$ can significantly enhanced the luminescence intensity by about 4.7 times when the best concentration is $9 \%$.This phosphor is a red phosphor that can be matched with the blue LED. And it can be doped in traditional white LED (blue LED + yellow phosphor YAG: Ce) to increase the red-light emission to compensate for the low color rendering defects.
\end{abstract}

\section{KEYWORDS}

White LED, Phosphor, Molybdate.

\section{INTRODUCTION}

White LEDs, because of the excellent properties, eg. small size, low power consumption, high efficiency, long durability, fast response and lack of toxic mercury, are considered as next generation solid-state lighting resource [1-3]. Currently, there are two methods for synthesizing white LEDs: one is that using a blue LED chip and a yellow-emitting $\mathrm{Y}_{3} \mathrm{Al}_{5} \mathrm{O}_{12}$ : $\mathrm{Ce}^{3+}$ (YAG: $\mathrm{Ce}^{3+}$ ) phosphor to combine white light, but in this way, white light emission spectrum lack of red light, and at high current yellow light changes slower than blue light changes, so color rendering performance is not good, and it has limitations in the application; Another way is that use near ultraviolet (UV) InGaN chip excite three-color phosphors. the disadvantage of the method is that the phosphor has lower luminous efficiency in the near ultraviolet and color rendering index [4].

Based on these, the study of highly efficient and stable red phosphors has become an important task. Because of their attractive chemical, optical and structural properties, molybdates as hosts for luminescence material have received extensive interests. For example, Ana Paula A have reported the luminescence of $\mathrm{Eu}^{3+}$ doped $\mathrm{SrMoO}_{4}$ by complex polymerization (CP) method [5]. The effect of $\mathrm{Eu}^{3+}$ ion doping on the luminescence properties was studied. $\mathrm{Eu}^{3+}$ ions doped tungsten or molybdate oxides are representative red-emitting phosphors for basic luminescent materials in LED because of its high brightness and high efficiency. In this work, aiming to improve the emission intensity of the phosphor, we have prepared a new type of molybdate phosphor successfully. And the influence of charge compensating agent was investigated systematically.

\section{EXPERIMENTAL}

$\mathrm{Eu}^{3+}$ doped molybdate $\mathrm{SrMoO}_{4}$ was prepared through conventional solidstate reaction. Firstly, the starting materials $\mathrm{SrCO}_{3}, \mathrm{H}_{2} \mathrm{MoO}_{4}, \mathrm{Eu}_{2} \mathrm{O}_{3}$ were analytical grade regents, thoroughly mixed in light of stoichiometric ratio of $\mathrm{SrMoO}_{4}$ formula. Furthermore, $\mathrm{Li}_{2} \mathrm{CO}_{3}, \mathrm{Na}_{2} \mathrm{CO}_{3}$, and $\mathrm{K}_{2} \mathrm{CO}_{3}$ as the charge compensators regents were added to the raw materials for the sample synthesis reaction [6]. The stoichiometric raw materials were thoroughly mixed in an agate mortar, then the mixture was transferred to a corundum crucible and heated at different temperatures and different times in air atmosphere.
X-ray diffraction (XRD) patterns were collected on a XRD-7000 powder diffractometer with CuKa radiation ( $\lambda=0.15405 \mathrm{~nm}$ ) at $45 \mathrm{kV}$ and $40 \mathrm{~mA}$, and the data were recorded in the range $2 \theta=10-80^{\circ}$ to analyze the crystal structure and phase purity of samples [7]. The photoluminescence (PL) and excitation (PLE) spectra were measured using an RF-5301PC fluorescence spectrophotometer assembled with $150 \mathrm{~W}$ Xe lamp. The measuring range is $220 \sim 750 \mathrm{~nm} .340 \mathrm{~nm}$ and $420 \mathrm{~nm}$ filters were used, and the test was performed with a slit $\mathrm{EX}=1.5$ and $\mathrm{EM}=1.5$.

\section{RESULTS AND DISCUSSION}

\subsection{Powder X-ray diffraction}

Figure 1 (a) shows the wide-angle powder X-ray diffraction patterns of $\mathrm{SrMoO}_{4}$ phosphors with $30 \% \mathrm{Eu}^{3+}$ doped, and the sample was prepared through the solid-state reaction fired at $900^{\circ} \mathrm{C}$ for $4 \mathrm{~h}$. All the positions of the diffraction peaks of the sample were agree well with the standard pattern (JCPDS File No. 08-0482), which is shown in Figure 1a. The Eu ${ }^{3+}$ ion has been incorporated into the $\mathrm{Sr}^{2+}$ ion in the host lattice of $\mathrm{SrMoO}_{4}$. The intense diffraction peaks confirmed the formation of single phase compounds [8].

The XRD analysis shows that the corresponding lattice constants of $\mathrm{SrMoO}_{4}$ are calculated to be $a=0.5394 \mathrm{~nm}, \quad c=1.202 \mathrm{~nm}, \alpha=\beta=\gamma=90^{\circ}$, I41/a (88) space group, which is attributed to scheelite $\mathrm{SrMoO}_{4}$ structure, In $\mathrm{SrMoO}_{4}: \mathrm{Eu}^{3+}$, each $\mathrm{Sr}^{2+}$ atom was bonded to eight $\mathrm{O}$ atoms to form [ $\left.\mathrm{SrO}_{8}\right]$ unit [9]. And the $\mathrm{Eu}^{3+}$ atoms substitute partly the lattice sites of the $\mathrm{Sr}^{2+}$ ions, which are coordinated with eight $\mathrm{O}$ atoms. Meanwhile, also, the Mo atoms were coordinated by four 0 atoms $\left[\mathrm{MoO}_{4}\right]$ clusters. The structure of $\mathrm{SrMoO}_{4}$ is shown in Figure 1(b). 


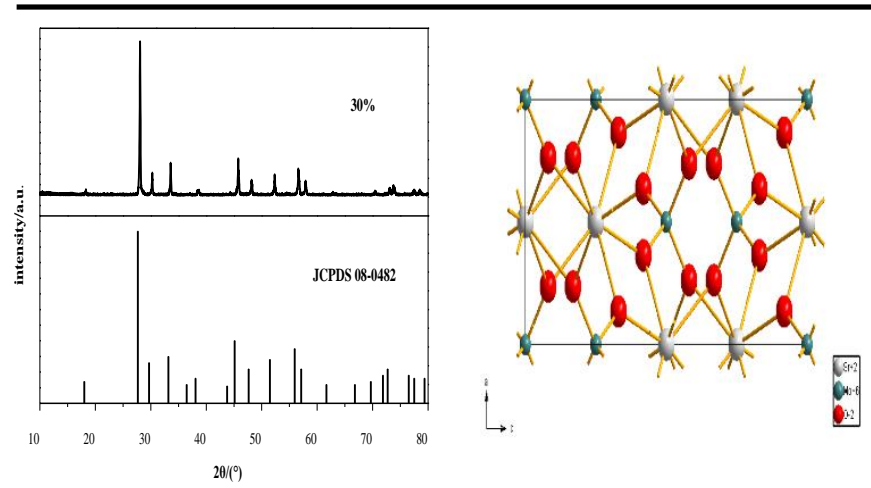

3.3 Effect of Charge Compensator on Luminescence Properties of Phosphors

The excitation and emission spectra of $\mathrm{Sr}_{0.94} \mathrm{MoO}_{4}: 0.03 \mathrm{Eu}^{3+}, 0.03 \mathrm{~A}\left(\mathrm{~A}^{2} \mathrm{Li}^{+}\right.$, $\mathrm{Na}^{+}, \mathrm{K}^{+}, \mathrm{Cl}^{-}$) samples are shown in Figure 4 (a) and (b), which is similar to $\mathrm{Sr}_{0.97} \mathrm{MoO}_{4}: 0.03 \mathrm{Eu}^{3+}$. However, as well as charge compensating agent was not added, the spectral intensity of the synthesized sample was relatively weak. the intensity of the emitted light of the synthesized sample was significantly enhanced on adding the charge compensating agent.The effect of several charge compensators on the spectral intensity enhancement is $\mathrm{Li}^{+}<\mathrm{Cl}^{-}<\mathrm{K}^{+}<\mathrm{Na}^{+}$. Because of the similar radius of $\mathrm{Na}^{+}$ions $(0.102 \mathrm{~nm})$ and that of $\mathrm{Sr}^{2+}$ ions $(0.118 \mathrm{~nm})$ compared with $\mathrm{Cl}-(0.181$ $\mathrm{nm}), \mathrm{K}^{+}(0.138 \mathrm{~nm})$, and $\mathrm{Li}^{+}(0.076 \mathrm{~nm}), \mathrm{Na}^{+}$ion has the best enhancement effect on the spectrum, which could effectively fit into the lattice sites of Sr. In this case, the emission probability of $\mathrm{Eu}^{3+}$ ions is significantly increased, and the luminescence intensity of phosphor $\mathrm{Sr}_{0.97} \mathrm{MoO}_{4}$ : $0.03 \mathrm{Eu}^{3+}$ is significantly enhanced, also. $\mathrm{SrMoO}_{4}: \mathrm{Eu}^{3+}$

\subsection{Photoluminescence Properties of $\mathrm{SrMoO}_{4}: \mathrm{Eu}^{3+} \mathrm{Phosphors}$}

Figure 2 shows the excitation and emission spectra of $\mathrm{SrMoO}_{4}$ phosphor. The PL spectrum with a peak at $615 \mathrm{~nm}$ was recorded by monitoring the excitation spectrum $464 \mathrm{~nm}$, which was assigned as the transition originating from the allowed ${ }^{5} \mathrm{D}_{0}{ }^{-7} \mathrm{~F}_{2}$ level of $\mathrm{Eu}^{3+}$.The corresponding PLE spectra bands at $464 \mathrm{~nm}$ from the ${ }^{7} F_{0} \rightarrow{ }^{5} D_{2}$ transition of $\mathrm{Eu}^{3+}$ when monitored at $615 \mathrm{~nm}$.

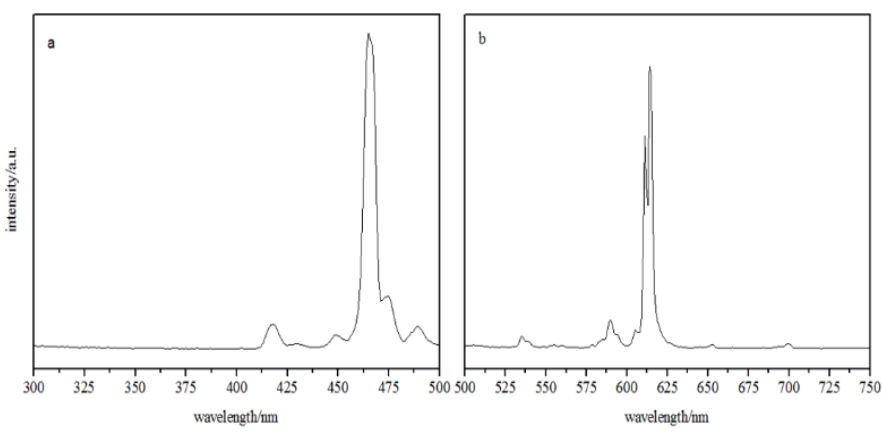

Figure 2: (a)PL excitation and (b) emission spectra of $\mathrm{SrMoO}_{4}$ red phosphor

As can be seen from the figure 3(a) and (b), when the concentration of $\mathrm{Eu}^{3+}$ ions is $3 \%$, the luminescence intensity of the $\mathrm{Sr}_{1-\mathrm{x}} \mathrm{MoO}_{4}: \mathrm{xEu}^{3+}$ sample is the weakest. The light intensity of the sample increases with the increase of the molar concentration of $\mathrm{Eu}^{3+}$ ions. When the concentration of $\mathrm{Eu}^{3+}$ ions is $30 \%$, the peak intensity of the sample peaks. If you continue to increase the proportion of $\mathrm{Eu}^{3+}$ ions, the emission peak intensity of the sample will tend to decrease. This is due to the concentration quenching effect between $\mathrm{Eu}^{3+}$ ions as the molar concentration of $\mathrm{Eu}^{3+}$ ions continue to increase. The proportion of $\mathrm{Eu}^{3+}$ ions in the host crystal lattice gradually increases, resulting in a constant reduction in the distance between $\mathrm{Eu}^{3+}$ ions. And as well as the distance between the luminescent center $\mathrm{Eu}^{3+}$ ions decreases, $\mathrm{Eu}^{3+}$ ions begin to interact with each other. As a result, no radiation energy transfer occurs $\mathrm{Eu}^{3+}$ ions each other, which is considered that the energy is consumed between $\mathrm{Eu}^{3+}$ ions. The nergy is not released in the form of light, which results in the loss of energy. This phenomenon also shows the energy transfer between $\mathrm{Eu}^{3+}$ ions in $\mathrm{Sr}_{1-\mathrm{x}} \mathrm{MoO}_{4}: \mathrm{xEu}^{3+}$.

(a)

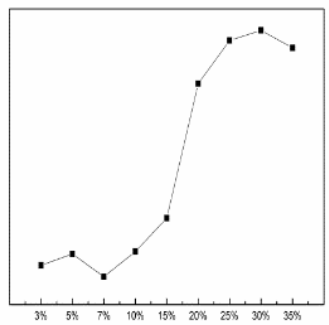

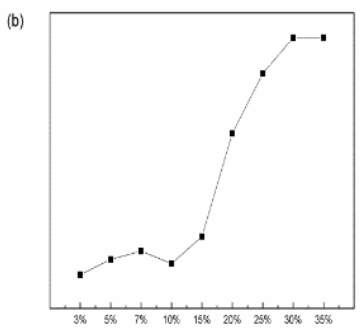

Figure 3: (a)the linear graph of emission intensity vs. Eu ${ }^{3+}$ concentrations, (b) the linear graph of excitation intensity vs.Eu ${ }^{3+}$
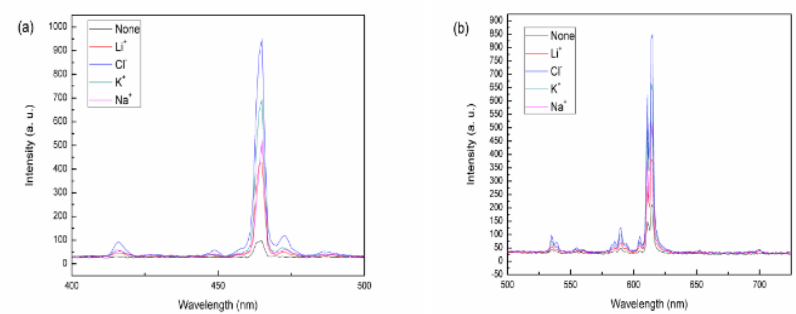

Figure 4: (a) Photoluminescence excitation spectra of $\mathrm{SrMoO}_{4}: \mathrm{Eu}^{3+}$ phosphor codoped with different alkali-metal ions $\left(\mathrm{Li}^{+}, \mathrm{Na}^{+}\right.$, and $\left.\mathrm{K}^{+}\right)$for charge compensation, at an emission wavelength of $615 \mathrm{~nm}$.(b) Emission spectra of $\mathrm{SrMO}_{4}: \mathrm{Eu}^{3+}$ phosphor codoped with different alkali-metal ions $\left(\mathrm{Li}^{+}, \mathrm{Na}^{+}, \mathrm{K}^{+}\right)$for charge compensation at excitation wavelengths of 464 nm.

Figure 5 shows the effect of $\mathrm{Na}^{+}$ions with different concentrations on the luminescence intensity of $\mathrm{Sr}_{0.97} \mathrm{MoO}_{4}: 0.03 \mathrm{Eu}^{3+}$ phosphors. The luminescence intensity of the sample increases with the increasing of $\mathrm{Na}^{+}$ ion. And on the addition amount of $\mathrm{Na}^{+}$ion is $9 \%$, the enhancement effect of the emission peak intensity is best. It is considered that the volume of $\mathrm{Na}^{+}$is smaller than other ions, which occupying the position in the crystal lattice, and it fill in the gap, also. Crystal field environment around $\mathrm{Sr}^{2+}$ ions and $\mathrm{Eu}^{3+}$ ions has been changed. The luminescence intensity (973.258 a.u.) of $\mathrm{Sr}_{0.88} \mathrm{MoO}_{4}: 0.03 \mathrm{Eu}^{3+}, 0.09 \mathrm{Na}^{+}$is about 4.7 times larger than that of $\mathrm{Sr}_{0.97} \mathrm{MoO}_{4}: 0.03 \mathrm{Eu}^{3+}$ (200.482a.u.). The above results show that adding a suitable charge compensator could greatly improve the performance of phosphor $\mathrm{Sr}_{0.97} \mathrm{MoO}_{4}: 0.03 \mathrm{Eu}^{3+}$. In addition, the color coordinate of the sample $\mathrm{Sr}_{0.97} \mathrm{MoO}_{4}: 0.03 \mathrm{Eu}^{3+}$ was changed from $(0.495,0.484)$ with no charge compensating agent added to $(0.552,0.435)$ with $9 \% \mathrm{Na}_{2} \mathrm{CO}_{3}$ added, and the color coordinate shifted significantly to the red light region.

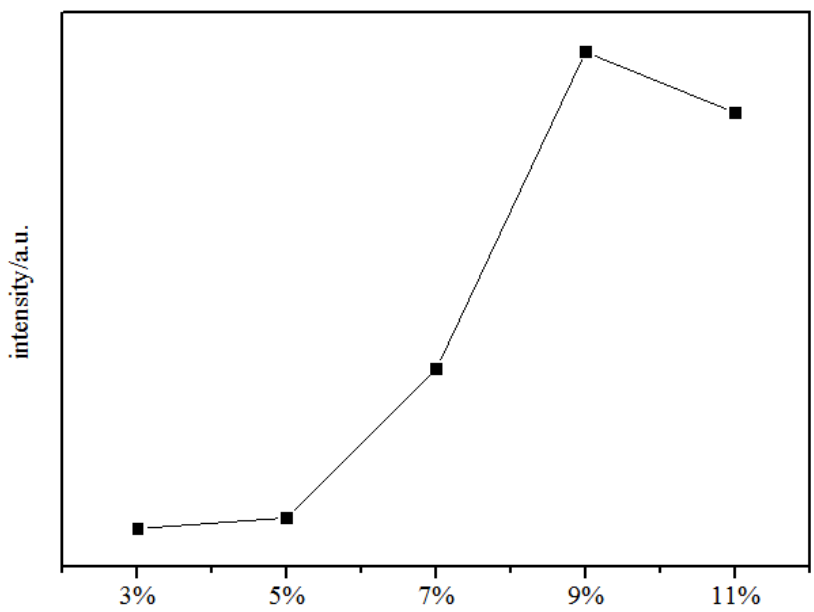

Figure 5: Luminous intensity comparison chart of $\mathrm{Sr}_{0.97-x} \mathrm{MoO}_{4}: 0.03 \mathrm{Eu}^{3+}$, $x \mathrm{Na}^{+}(\mathrm{x}=0.03,0.05, \quad 0.07,0.09, \quad 0.11)$ concentrations 


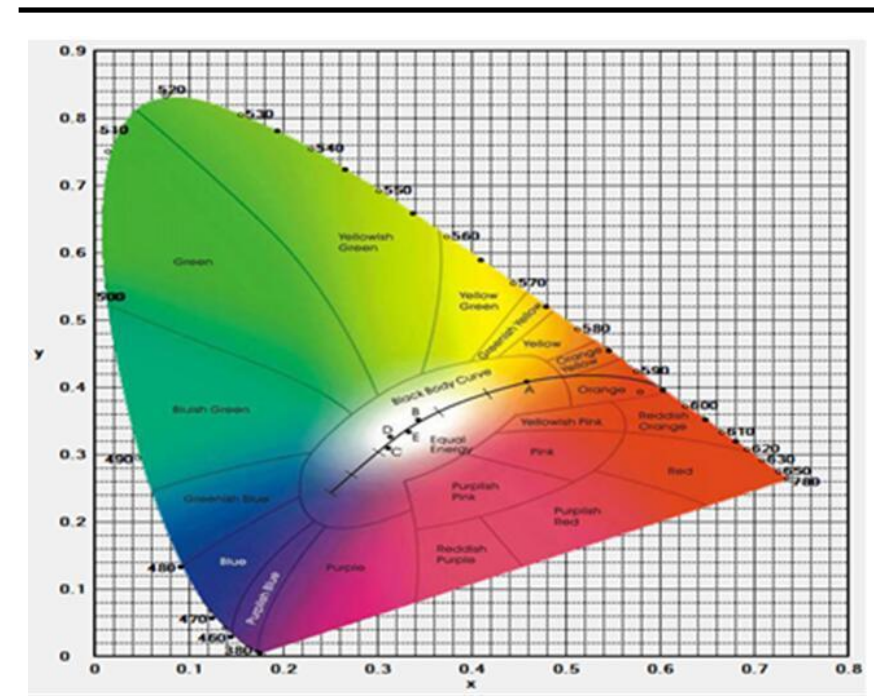

Figure 6: CIE 1931 chromaticity diagram for $\mathrm{SrMoO}_{4}: \mathrm{Eu}^{3+}$ phosphor

\section{REFERENCES}

[1] Shivakumara, C., Saraf, R. 2015. Eu3+-activated SrMo04 phosphors for white LEDs applications: Synthesis and structural characterization [J]. Optical Mater., 42, 178-186.

[2] Chen, J.Y., Guo, C.F., Yang, Z. 2016. Li2SrSiO4:Ce3+, Pr3+ Phosphor with blue, red, and near-infrared emissions used for plant growth LED [J]. J. Am.
Ceram. Soc., 99 (1), 218-225.

[3] Qin, L., Huang, Y. 2012. The red-emitting phosphors of Eu3+-activated MR2(Mo04)4 (M = Ba, Sr, Ca; $=$ = La3+, Gd3+, Y3+) for light emitting diodes [J]. Materials Research Bulletin, 47, 4498-4502.

[4] Marques, A.P.A., Tanaka, M.T.S., Longo, E., Leite, E.R., Rosa, I.L.V. 2011. The Role of the Eu3+ Concentration on the SrMo04: Eu Phosphor Properties: Synthesis, Characterization and Photophysical Studies [J]. Journal of Fluorescence, 21 (3), 893-899.

[5] Talewar, R.A., Joshi, C.P. 2016. Near infrared emission and energy transfer in Eu2+ - Nd3+ co-doped Ca2BO3Cl [J]. Optical Materials, 55, 4448.

[6] Gupta, S.K., Sudarshan, K. 2018. Deciphering the Role of Charge Compensator in Optical Properties of SrW04:Eu3+:A $(\mathrm{A}=\mathrm{Li}+, \mathrm{Na}+, \mathrm{K}+)$ : Spectroscopic Insight Using Photoluminescence, Positron Annihilation, and X-ray Absorption [J]. Inorganic chemistry, 57, 821-832.

[7] Cho, T. 2017. Innovative Micro-Dust Reduction Technologies. Acta Chemica Malaysia, 1 (1), 04-07.

[8] Bao, X., Zhou, S. 2013. Color tunable phosphor CaMoO4:Eu3+,Li+ via energy transfer of Mo042--Eu3+ dependent on morphology and doping concentration [J]. Materials Research Bulletin, Mater. Res. Bull., 48 (3), 1034-1039.

[9] Zhang, N., Wang, D.J., Li, L. 2006. YAG:Ce phosphors for WLED via nanopseudoboehmite sol-gel route [J]. J. Rare Earths, 24 (3), 294-297. 